\title{
The Ability of a Single Serum Progesterone Measurement to Predict the Prognosis of First Trimester Pregnancy
}

\author{
Mehmet Nafi SAKAR1, Deniz BALSAK², Sureyya DEMIR ${ }^{3}$, Mehmet Sukru BUDAK ${ }^{4}$, Ali Emre TAHAOGLU4, \\ Sinan Emre GUNGOR 5 , Emrullah AKAY5 ${ }^{5}$, Bulent DEMIR \\ Diyarbakir, Turkey
}

\begin{abstract}
OBJECTIVE: There are cases where ultrasonographic evaluation is inadequate in determining firsttrimester healthy pregnancy. In these cases, both the patient and the clinician are involved in a worrying expectation. The single serum progesterone measurement was tried to predict pregnancy prognosis in short time period. This study evaluated the predictive value of a single serum progesterone measurement in first-trimester pregnancy loss.

STUDY DESIGN: A prospective case-control study was conducted between July 2013 and July 2014 in Tertiary Hospital. The study compared 106 patients with threatened abortion (vaginal bleeding or spotting) before 13 weeks of gestation with 110 healthy control pregnancies. Samples of serum progesterone were obtained on the day each patient was admitted to the hospital. A Beckman-Coulter macro-Enzymelinked immunoassay (ELISA) system was used to measure serum levels of progesterone (BeckmanCoulter, Ireland).

RESULTS: Progesterone levels were measured when the patients first visited the hospital and they were followed until the end of the first trimester. Progesterone levels differed significantly $(p=0.013)$ between the two groups. The spontaneous abortion rate was significantly $(p=0.044)$ higher in the case group. Progesterone levels differed significantly $(p=0.001)$ between ongoing pregnancy and spontaneous abortion groups. Using a cut-off level of $10.7 \mathrm{ng} / \mathrm{mL}$, the sensitivity, specificity, and positive and negative predictive values were $92.1 \%, 44 \%, 92.6 \%$, and $42.3 \%$, respectively, for viable pregnancies.
\end{abstract}

CONCLUSION: A single measurement of progesterone levels in serum can predict the prognosis of a viable first-trimester pregnancy, while it is less effective for identifying non-viable pregnancies.

Keywords: First trimester, Prognosis, Serum progesterone

Gynecol Obstet Reprod Med 2020;26(1):1-5

\section{Introduction}

Early pregnancy loss is defined as a loss before 13 weeks of gestation. Wilcox et al. determined that the pregnancy loss rate after implantation was $31 \%$ over 707 menstrual cycles in 221 healthy women and found that two-thirds of early preg-

${ }^{1}$ Department of Obstetrics and Gynecology, Memorial Hospital, Diyarbakir, Turkey

2 Department of Obstetrics and Gynecology, School of Medicine, Halic University, Istanbul, Turkey

3 Department of Obstetrics and Gynecology, School of Medicine, Dokuz Eylul University, Istanbul, Turkey

${ }^{4}$ Department of Obstetrics and Gynecology, Gazi Yasargil Education and Research Hospital, Health Sciences University, Diyarbakir, Turkey

5 Department of Obstetrics and Gynecology, Suleymaniye Education and Research Hospital, Health Sciences University, Istanbul, Turkey

${ }^{6}$ Department of Obstetrics and Gynecology, School of Medicine, Onsekiz Mart University, Istanbul, Turkey

Address of Correspondence: Mehmet Nafi Sakar

Memorial Diyarbakir Hospital, Department of Obstetrics and Gynecology, 21070 Diyarbakir, Turkey

nafisakar@gmail.com

Submitted for Publication:

28.03.2019

Revised for Publication:

15.08 .2019

Accepted for Publication: nancies were lost before pregnancy was diagnosed (1) Spontaneous pregnancy loss seems in up to $20 \%$ of recognized pregnancies and it is high rate (2). Above $80 \%$ of spontaneous abortion occur before 12 weeks of gestation $(1,3)$. Of all abortions, $50 \%$ are anembryonic abortions with no embryonic findings (4). The etiology of the other $50 \%$ is related to embryonic or placental defects. Aneuploidy is seen in $50 \%$ of the latter ( $25 \%$ of all abortions).

Clinically, abortions are classified as complete, incomplete, inevitable, and missed. Ultrasonography (USG), clinical findings, and laboratory markers are used to confirm preg-

ORCID IDs of the authors:

MNS:0000-0002-3260-1041, DB: 0000-0003-3140-8298 SD: 0000-0002-4051-3703, MSB:0000-0001-7328-4188 AET: 0000-0002-3460-3438, SEG:0000-0002-0689-1743 EA: 0000-0003-3792-7777, BD: 0000-0001-6608-9886

\begin{tabular}{|c|c|}
\hline Quick Response Code: & Access this article online \\
\cline { 2 - 2 } & Website: www.gorm.com.tr \\
& e- mail: info@gorm.com.tr \\
\cline { 2 - 3 } & DOI:10.21613/GORM.2019.942 \\
\hline
\end{tabular}

How to cite this article: Sakar MN. Balsak D. Demir S. Budak MS. Tahaoglu AE. Gungor SE. Akay E. Demir B. The Ability of a Single Serum Progesterone Measurement to Predict the Prognosis of First Trimester Pregnancy. Gynecol Obstet Reprod Med 2020;26(1):1-5 
nancy. In the early stages of pregnancy, USG and clinical findings may provide confounding evidence (5). The USG findings are sonographer dependent, and the determination of early pregnancy is not repeatable. In these situations, both the patient and the clinician are involved in a worrying expectation. Consequently, a reliable marker of viable early pregnancy is required. Progesterone is a 21-carbon steroid hormone that is produced by granulosa cells. It is essential for pregnancy, implantation, and decidualization (6). It also inhibits uterine contractions and plays a role in the immunological rejection of pregnancy.

Some studies have demonstrated that progesterone is a very specific biomarker of non-viable and viable pregnancies $(7,8)$, although its different cut-off values decrease its diagnostic power (9-11).

In this study, we examined the ability of a single measurement of progesterone levels from serum samples for discriminating between viable and non-viable pregnancies in patients with threatened abortion and asymptomatic pregnancies. The main aim of our study was to predict the first-trimester prognosis with a single serum progesterone value. The difference between our study and other studies is the inclusion of both symptomatic and asymptomatic pregnant.

\section{Material and Method}

This prospective case-control study was carried out between June 2013 and June 2014 in the Department of Obstetrics and Gynecology of Suleymaniye Education and Research Hospital, Istanbul, Turkey. The study included 106 patients with threatened abortion (with vaginal bleeding or spotting) before 13 weeks of gestation and 110 healthy control pregnancies. Double blinding performed between technicians performing enzyme-linked immunoassay (ELISA) and clinicians looking after the patients. Exclusion criteria were cervical polyps, cervical cancer, trauma, assisted reproductive technology (ART), multiple pregnancy, and ectopic pregnancy. Women treated with progesterone or any other medications were also excluded.

The study was approved by the ethical review committee of Haseki Education and Research Hospital, Istanbul, Turkey (Approval number: 29). Written informed consent was obtained from all participants. The study was conducted according to the International Conference of Harmonization/Good Clinical Practice (ICH/GCP) guidelines and the latest version of the Helsinki Declaration by World Medical. Age, body mass index (BMI), parity, history of abortion, and age of a pregnancy (according to the last menstrual cycle) were noted. All pregnancies were followed until the end of the first trimester. A Beckman-Coulter macro-Enzyme-linked immunoassay (ELISA) system was used to measure serum levels of progesterone (Beckman-Coulter, Ireland). Samples were obtained on the day each patient was admitted to the hospital.

\section{Statistical analysis}

Statistical analyses were conducted using IBM SPSS statistics 22.0 (IBM SPSS, Turkey). The conformity of the parameters to the normal distribution was evaluated by the Shapiro-Wilks test. Descriptive statistics and the Student's ttest, Mann-Whitney U test, and chi-square test were used to compare groups. The cut-off point was determined according to an area under the receiver operating characteristics curve (AUC) and the 95\% confidence interval was calculated; $p<0.05$ was considered significant. For power calculation, we used the $\mathrm{G}^{*}$ Power program. According to serum progesterone cut-off value, when effect size for viable pregnancy rates continuing at the end of the first trimester was taken $d=0.699$; the minimum number of samples was determined as $n=68$ for power $=0.80$ and $\alpha=0.05$.

\section{Results}

We compared 106 patients with threatened abortion and 110 healthy pregnancies. The mean ages were $27.02 \pm 5.02$ and $27.43 \pm 4.63$ years in the patient and control groups, respectively (Table I, $p=0.535$ ). Gravidity, parity, BMI, and history of abortion did not differ between the two groups (Table I, all $p>0.05)$. Serum progesterone levels are higher in the controls group (Table I, $p=0.013$ ). Viable pregnancy rate is higher in the controls group when compared threatened abortion group (Table I, $p=0.044)$. When progesterone levels were compared according to pregnancy prognosis (viable or non-viable), they were significantly higher in all subjects (patients and controls) with viable pregnancies (Table II, $p=0.001$ ). In all participants, when viable and non-viable pregnancies were compared according to progesterone levels using the ROC curve (Figure 1 ), the sensitivity, specificity, positive predictive value (PPV) and negative predictive value (NPV) were 92.1\%, 44\%,

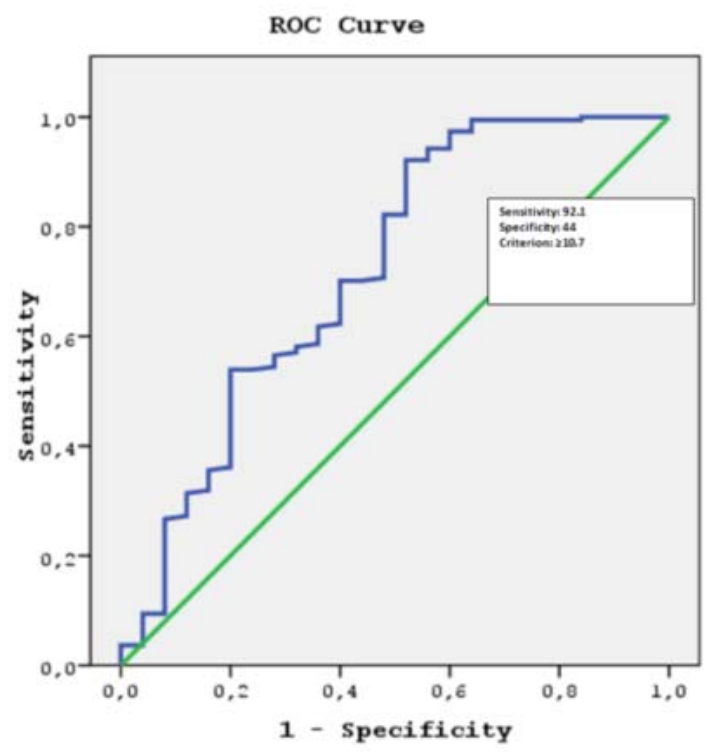

Figure 1: Association between single serum progesterone levels and prognosis of first-trimester pregnancy. This figure showed the ROC curve of progesterone cut-off. 
Table I: Demographical and clinical characteristics of the study population

\begin{tabular}{|c|c|c|c|}
\hline & $\begin{array}{l}\text { Threatened Abortion } \\
\qquad(n=106)\end{array}$ & $\begin{array}{l}\text { Controls } \\
(n=110)\end{array}$ & $p$ \\
\hline Age (year) $)_{\text {mean } \pm S D}$ & $27.02 \pm 5.02$ & $27.43 \pm 4.63$ & 10.535 \\
\hline Body Mass Index $\left(\mathrm{kg} / \mathrm{m}^{2}\right)_{\text {mean } \pm S D}$ & $24.74 \pm 4.69$ & $24.49 \pm 4.12$ & ${ }^{1} 0.678$ \\
\hline Graviditymean \pm SD (median) & $2.47 \pm 1.72(2)$ & $2.35 \pm 1.32(2)$ & ${ }^{2} 0.820$ \\
\hline Paritymean $\pm S D$ (median) & $1.10 \pm 1.39(1)$ & $1.06 \pm 1.10(1)$ & 20.625 \\
\hline \multicolumn{4}{|l|}{${ }^{\Phi}$ History of Abortionn (\%) } \\
\hline Absent of history $n(\%)$ & $82(77.4 \%)$ & $89(80.9 \%)$ & ${ }^{3} 0.521$ \\
\hline Present of history $\mathrm{n}(\%)$ & $24(22.6 \%)$ & $21(19.1 \%)$ & \\
\hline Gestational age of progesterone measurement (week) meanıss (median) & $8.03 \pm 2.12(8)$ & $8.21 \pm 1.80(8)$ & 20.391 \\
\hline Serum progesterone level (ng/mL) & $17.07 \pm 8.37(14.55)$ & $18.79 \pm 6.46(17.2)$ & ${ }^{2} 0.013^{*}$ \\
\hline \multicolumn{4}{|l|}{ Prognosis of first-trimester pregnancy } \\
\hline Non-viable pregnancies & $17(16 \%)$ & $8(7.3 \%)$ & ${ }^{3} 0.044^{*}$ \\
\hline Viable pregnancies & $89(84 \%)$ & $102(92.7 \%)$ & \\
\hline \multicolumn{4}{|c|}{ Distribution of participants according to serum progesterone cut-off (ng/mL) } \\
\hline$\geq 10.7$ & $84(79.2 \%)$ & $106(96.4 \%)$ & ${ }^{3} 0.000^{*}$ \\
\hline$<10.7$ & $22(20.8 \%)$ & $4(3.6 \%)$ & ** \\
\hline
\end{tabular}

${ }^{1}$ Studen $t$ Test, ${ }^{2}$ Mann-Whitney $\cup$ Test, ${ }^{3}$ Chi-square test, ${ }^{\Phi}$ Maximum 1 abortion, ${ }^{*} p<0.05,{ }^{* *} p<0.01,{ }^{* * *} p<0.001$

Table II: Association between single serum progesterone level and prognosis of first-trimester pregnancy

\begin{tabular}{|c|c|c|c|}
\hline & \multirow{2}{*}{$\begin{array}{l}\text { Prognosis of first- } \\
\text { trimester pregnancy }\end{array}$} & Serum progesterone level (ng/mL) & \multirow{2}{*}{$p$} \\
\hline & & mean $\pm S D$ (median) & \\
\hline \multirow[t]{2}{*}{ Threatened Abortion } & Non-viable & $12.62 \pm 9.35(7.77)$ & \multirow[b]{2}{*}{$0.003^{* *}$} \\
\hline & Viable & $17.92 \pm 7.95(15.5)$ & \\
\hline \multirow[t]{2}{*}{ Controls } & Non-viable & $14.53 \pm 4.06(15.35)$ & \multirow[b]{2}{*}{$0.037^{*}$} \\
\hline & Viable & $19.12 \pm 6.51(17.55)$ & \\
\hline \multirow[t]{2}{*}{ All participants } & Non-viable & $13.23 \pm 7.99(12.2)$ & \multirow{2}{*}{$0.001^{* *}$} \\
\hline & Viable & $18.56 \pm 7.22(16.8)$ & \\
\hline
\end{tabular}

Mann-Whitney U Test, ${ }^{*} p<0.05,{ }^{* *} p<0.01$

$92.6 \%$, and $42.3 \%$, respectively, for viable pregnancies using a progesterone cut-off value of $10.7 \mathrm{ng} / \mathrm{mL} .79 .2 \%$ of the threatened abortion group and $96.4 \%$ of the controls group had a serum progesterone level $\geq 10.7 \mathrm{ng} / \mathrm{mL} ; 20.8 \%$ of the threatened abortion group and $3.6 \%$ of the controls group had a serum progesterone level of $<10.7 \mathrm{ng} / \mathrm{mL}$. The weakness of the test was that the specificity was low. The AUC was 0.719 (95\% CI 0.596-0.842) for the serum progesterone level.

\section{Discussion}

Numerous different biochemical parameters are being explored to predict early pregnancy prognosis. Early pregnancy is maintained by hormones and endocrine-immune interactions (12). Progesterone plays an important role during implantation; provides decidualization, controls uterine contraction, and increases the immune tolerance of the mother against the fetus (13). High serum progesterone levels have a protec- tive effect against spontaneous pregnancy losses, whereas low serum progesterone levels increase spontaneous pregnancy loss risk especially in first trimester patients with threatened abortion (14).

This study investigated the predictive value of a single measurement of progesterone levels from serum in patients with threatened abortion and asymptomatic pregnancies. Levels were significantly higher in viable pregnancies than in non-viable pregnancies in both groups. Clinical features of threatened abortion (vaginal bleeding or spotting) were also significant predictors for the prognosis of pregnancy. While progesterone levels were effective for identifying viable pregnancies in both groups, they were not effective for identifying non-viable pregnancies. The main aim of our study was to predict the first-trimester prognosis with a single serum progesterone value. The difference between our study and other studies is the inclusion of both symptomatic and asymptomatic 
pregnant. The studies performed in this area are usually done with symptomatic pregnant (14-17), and very few studies with asymptomatic pregnant $(18,19)$.

Many studies have reported that progesterone levels are an effective marker $(7,20,21)$. We found that the cut-off level for diagnosing viable pregnancies was $10.7 \mathrm{ng} / \mathrm{mL}$, which had a sensitivity, specificity, PPV, and NPV of 92.1\%, 44\%, 92.6\%, and $42.3 \%$, respectively. One weakness of this test was its low specificity for identifying non-viable pregnancies. In their study, Kelekci et al. determined cut off value as $15 \mathrm{ng} / \mathrm{mL}$ for serum progesterone. They indicated that when the cut-off value increased, sensitivity increased and specificity decreased; when cut-off value decreased, sensitivity decreased and specificity increased (19). The Royal College of Obstetricians and Gynaecologists' guideline stated that the value of single serum progesterone in early pregnancy is useful for predicting the outcome of pregnancy, and when serum progesterone threshold is $20 \mathrm{nmol} / \mathrm{L}$ (about $6.2 \mathrm{ng} / \mathrm{mL}$ ), it can be predicted non-viable pregnancies with $93 \%$ sensitivity, $94 \%$ specificity in symptomatic pregnant (22). In the study of Abdelazim et al. when the serum progesterone cut-off level was $10 \mathrm{ng} / \mathrm{ml}$, it was $79.3 \%$ sensitive for non-viable pregnancy diagnosis, $93.3 \%$ specific for viable pregnancy diagnosis; when serum progesterone cut-off level was $20 \mathrm{ng} / \mathrm{ml}$, it was $95.1 \%$ sensitive for non-viable pregnancy diagnosis and $98.9 \%$ specific for viable pregnancy diagnosis (23). Elson et al. reported that the $25 \mathrm{ng} / \mathrm{mL}$ serum progesterone cut-off value obtained by ROC curve statistical analysis predicts viable pregnancies with $100 \%$ sensitivity and $43 \%$ specificity (5). In our study, cut-off value specificity was similar to that of Elson et al. Different cut-off results and different specificity among studies may be due to differences in measurement, standardization, and performance of progesterone assay (16), and differences in progesterone value in a different population of women of geographical origin (24).

The cut-off level that distinguished between viable and non-viable pregnancies was similar to that of many previous studies $(7,15,11,25)$. al-Sebai et al. (7) reported a significantly lower progesterone level in non-viable and ectopic pregnancies; using a cutoff of $45 \mathrm{nmol} / \mathrm{L}(14.1 \mathrm{ng} / \mathrm{mL})$, the sensitivity and specificity were $87.6 \%$ and $87.5 \%$, respectively. Using a cut-off $11.5 \mathrm{ng} / \mathrm{mL}, \mathrm{Al}$ Mohamady et al. reported a specificity of $97.5 \%$ and sensitivity of $100 \%$ (15). Hanita and Hanisah reported that a progesterone cut-off of $32.7 \mathrm{ng} / \mathrm{mL}$, which was much higher than in other studies, had a sensitivity of $92 \%$ and specificity of $90 \%(16)$; they argued that the large difference in cut-off value was a result of geographic and measurement differences. Cowan et al. found that the most discriminative progesterone level was $10 \mathrm{ng} / \mathrm{mL}$, based on ROC curves, and the productivity of the test was maximal between 9 and $14 \mathrm{ng} / \mathrm{mL}(80 \%)$ (26). In that study, when the progesterone levels were below $10 \mathrm{ng} / \mathrm{mL}$, the predictive value was above $90 \%$ for abnormal pregnancy loss. A meta-analysis showed that a single progesterone measurement in early pregnancy with bleeding or pain and an inconclusive USG assessment can rule out a viable pregnancy (17). We found that a single progesterone measurement was sufficient to identify viable pregnancies in both patient and control groups.

Generally, serum levels of progesterone are above 25 $\mathrm{ng} / \mathrm{mL}$ in viable pregnancies (27), while $5 \mathrm{ng} / \mathrm{mL}$ indicates an abnormal pregnancy prognosis (28). More studies are needed to eliminate extreme cut-off levels such as $<5 \mathrm{ng} / \mathrm{mL}$ for nonviable and $>25 \mathrm{ng} / \mathrm{mL}$ for viable.

In conclusion, a single measurement of progesterone levels from serum in the first trimester is useful for identifying viable pregnancies, but cannot predict non-viable pregnancies.

Acknowledgments: Thanks to the assistant professor Ismail Yildiz from the Biostatistics department.

Funding: None.

The authors declare there is no conflict of interest.

Authors Contributions: MNS: Planned and conducted the study, participated to interpretation of the results and writing process. DB: Participated to interpretation of the results and writing process, SD: Participated to interpretation of the results and writing process, MSB: Participated to interpretation of the results and writing process, AET: Conducted the study, SEG:Conducted the study, EA: Conducted the study, BD. Contributed to the revision of the study.

\section{References}

1. Wilcox AJ, Weinberg CR, O'Connor JF, Baird DD, Schlatterer JP, Canfield RE, et al. Incidence of early loss of pregnancy. N Engl J Med. 1988;319(4):189-94.

2. Voedisch AJ, Frederick CE, Nicosia AF, Stovall TG. Early pregnancy loss and ectopic pregnancy. In: Berek JS, editor. Berek \& Novak's Gynecology, $15^{\text {th }}$ ed. Philadelphia: Lippincott Williams \& Wilkins; 2012. p. 619-51.

3. Wang X, Chen C, Wang L, Chen D, Guang W, French J. Conception, early pregnancy loss, and time to clinical pregnancy: a population-based prospective study. Fertil Steril. 2003;79(3):577-84.

4. Silver RM, Branch DW, Goldenberg R, Iams JD, Klebanoff MA. Nomenclature for pregnancy outcomes: time for a change. Obstet Gynecol. 2011;118(6):1402-08.

5. Elson J, Salim R, Tailor A, Banerjee S, Zosmer N, Jurkovic D. Prediction of early pregnancy viability in the absence of an ultrasonically detectable embryo. Ultrasound Obstet Gynecol. 2003;21(1):57-61.

6. Brar AK, Frank GR, Kessler CA, Cedars MI, Handwerger S. Progesterone-dependent decidualization of the human endometrium is mediated by cAMP. Endocrine. 1997;6(3):301-07.

7. al-Sebai MA, Kingsland CR, Diver M, Hipkin L, McFadyen IR. The role of a single progesterone measure- 
ment in the diagnosis of early pregnancy failure and the prognosis of fetal viability. Br J Obstet Gynecol. 1995; 102(5):364-69.

8. Phipps MG, Hogan JW, Peipert JF, Lambert-Messerlian GM, Canick JA, Seifer DB. Progesterone, inhibin and hCG multiple marker strategy to differentiate viable from nonviable pregnancies. Obstet Gynecol. 2000;95(2):22731.

9. Carson SA, Buster JE. Ectopicpregnancy. N Engl J Med. 1993;329(16):1174-81.

10. Midha U, Narang APS, Sofat IB, Avasthi K, Jain M. Serum progesterone levels in abortions. J Obstet Gynecol India. 2002;52(5):47-50.

11. Taghavi AH. Detection of changes of hCG, progesterone and estradiol serum levels in threatened abortion in the first three months of gestation. Iran J Endocrinol Metab. 2004;6(2):163-69.

12. Norwitz ER, Schust DJ, Fisher SJ. Implantation and the survival of early pregnancy. N Engl J Med. 2001;345 (19):1400-08.

13. Arck P, Hansen PJ, Mulac Jericevic B, Piccinni MP, Szekeres-Bartho J. Progesterone during pregnancy: endocrine-immune cross talk in mammalian species and the role of stress. Am J Reprod Immunol. 2007;58(3):268-79.

14. Lek SM, Ku CW, Allen JC Jr, Malhotra R, Tan NS, Østbye $\mathrm{T}$, et al. Validation of serum progesterone $<35 \mathrm{nmol} / \mathrm{L}$ as a predictor of miscarriage among women with threatened miscarriage. BMC Pregnancy Childbirth. 2017;17(1):78.

15. Al Mohamady M, Fattah GA, Elkattan E, Bayoumy R, Hamed DA. Correlation of serum ca-125 and progesterone levels with ultrasound markers in the prediction of pregnancy outcome in threatened miscarriage. Int J Fertil Steril. 2016;9(4):506-11.

16. Hanita O, Hanisah AH. Potential use of single measurement of serum progesterone in detecting early pregnancy failure. Malays J Pathol. 2012;34(1):41-46.

17. Verhaegen J, Gallos ID, van Mello NM, Abdel-Aziz M, Takwoingi Y, Harb H, et al. Accuracy of single progesterone test to predict early pregnancy outcome in women with pain or bleeding: meta-analysis of cohort studies. BMJ. 2012;345:e6077.

18. Daily CA, Laurent SL, Nunley WC Jr. The prognostic value of serum progesterone and quantitative beta-human chorionic gonadotropin in early human pregnancy. Am J Obstet Gynecol. 1994;171(2):380-83; discussion 383-84.
19. Kelekci S, Tokucoglu S, Alan H, Tekin G. Prognostic value single serum progesterone levels and combination of serum $\beta$-hCG levels in early pregnancy. T Klin J Gynecol Obst. 2002;12(6):438-41.

20. Yeko TR, Gorril MG, Hughes LH, Rodi IA, Buster JE, Sauer MV. Timely diagnosis of early ectopic pregnancy using a single blood progesterone measurement. Fertil Steril. 1987;48(6):1048-50.

21. Lavoué V, Huchon C, Deffieux X, Voltzenlogel MC, Vandenbroucke L, Levêque J. French guidelines for diagnostic criteria for nonviable pregnancy early in the first trimester and for management of threatened miscarriage and nonviable pregnancy (except uterine evacuation). J Gynecol Obstet Biol Reprod (Paris). 2014;43(10):776-93.

22. Hinshaw K, Fayyad A, Munjuluri P. The management of early pregnancy loss. Royal College of Obstetricians and Gynaecologists, 2006. (Green-top guideline No 25).

23. Abdelazim IA, Belal MM, Makhlouf HH. Relation between single serum progesterone assay and viability of the first trimester pregnancy. J Turk Ger Gynecol Assoc. 2013;14(2):68-71.

24. Vitzthum VJ, Bentley GR, Spielvogel H, Caceres E, Thornburg J, Jones L, et al. Salivary progesterone levels and rate of ovulation are significantly lower in poorer than in better-off urban-dwelling Bolivian women. Hum Reprod. 2002;17(7):1906-13.

25. Dumps P, Meisser A, Pons D, Morales MA, Anguenot JL, Campana A, et al. Accuracy of single measurements of pregnancy-associated plasma protein-A, human chorionic gonadotropin and progesterone in the diagnosis of early pregnancy failure. Eur J Obstet Gynecol Reprod Biol. 2002;100(2):174-80.

26. Cowan BD, Vandermolen DT, Long CA, Whitworth NS. Receiver-operator characteristic, efficiency analysis, and predictive value of serum progesterone concentration as a test for abnormal gestations. Am J Obstet Gynecol. 1992; 166(6 Pt 1):1729-34: discussion 1734-37.

27. Stovall TG, Ling FW, Cope BJ, Buster JE. Preventing ruptured ectopic pregnancy with a single serum progesterone. Am J Obstet Gynecol. 1989;160(6):1425-28: discussion 1428-31.

28. Stovall TG. Early pregnancy loss and ectopic pregnancy. In: Berek JS, editor. Novak's Gynecology, $13^{\text {th }}$ ed. Philadelphia: Lippincott Williams \&Wilkins; 2002. p. 507-42. 